Maša Đurišić

Original scientific paper

UDC: 37.018 .262

Primary school "Veselin Masleša"

DOI: $10.17810 / 2015.77$

Belgrade, Serbia

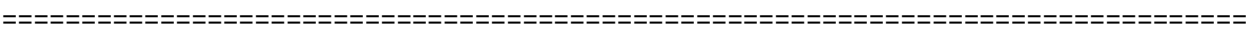

\title{
RELATIONS AND COMMUNICATION IN FAMILIES OF CHILDREN WITH EXTERNALIZING BEHAVIOR PROBLEMS
}

\begin{abstract}
Numerous studies have confirmed the connection between the family climate and various forms of externalizing behaviour problems, such as aggressive and violent behaviour, vandalism, skipping school and running away from home, substance abuse and others. Therefore, it is of particular importance to point out those risk factors, that according to the results of empirical studies are predictive for the occurrence and development of behavioural problems. This study shows the results of the research which aimed at determining the characteristics of family relationships in the families of children with externalizing behaviour problems. The sample consisted of 135 students, both gender, 11 to 14 years of age. Apart of the instruments for assessing emotional, social and behaviour problems of children and youth (ASEBA- YSR) was used for the evaluation of externalizing behaviour problems, while the FACES IV scale package was used to determine the quality of family relationships and communication within families. The results showed that students with externalizing behaviour problems live in the types of families where the quality of family relationships is low and which is characterized by poor connectivity and adaptability, poor communication and dissatisfaction.
\end{abstract}

Key words: family, family relations, communication, quality, externalizing problems.

\section{INTRODUCTION}

The family plays a very important role in the forming of a young personality and is one of the decisive factors in the development of the child. It represents the primary social environment in which most children spend their childhood, adolescence and early adulthood. The family is the first social group to which the child belongs, in which it acquires the first experiences, develops its potentials and forms attitudes. Relationships in the family influence the forming of personality traits such as: emotional stability, individual maturity, personal integrity development, preparedness to accept social roles. For this reason, the positive development of the children depends largely on the environment created within the family (Vilotijevic, 2002).

Extensive theoretical and empirical literature testifies that different aspects of relationships and communication within the family can contribute to the development of behaviour problems, including lack of intimacy and warmth, failure to respond to the needs of the child, expression of negative emotions, inadequate supervision of the child, strict punishment, setting unclear rules, poor attachment to the parents and others (Carlson et al., 1999; Matthys \& Lochman, 2010; McMahon et al., 2006). The results of research highlight the strict and 
coercive treatment of the children, inadequate supervision and monitoring, and the role of these aspects comes to the light in different developmental periods (Maughan, et al., 2000).

Risk representation is expressed in a significantly high degree and therefore imposes the need to undertake appropriate preventive activities, which should be directed at developing, strengthening and establishing of the protective factors. Positive family climate, quality relationships between parents and children, providing incentives and motivation, understanding, adequate control and supervision, positive communication, etc. can have a protective function in reducing problems in children's behaviour.

\section{THEORETICAL APROACH TO THE PROBLEM}

\section{Externalizing behaviour problems of students}

Externalizing behavioural problems relate to insufficiently controlled and to other people directed behaviours, involve conflicts with other people and social norms. Within the framework of the externalizing problems, two syndromes have been identified: aggressive behaviour syndrome and syndrome of the behaviour that violates the rules. The first syndrome involves various forms of oppositional behaviour and aggression, while the second syndrome involves only non-aggressive behaviours (Achenbach \& Rescorla, 2001).

Externalizing behaviour problems negatively affect the proper development and hinder the functioning of the child in all domains, show certain stability and represent the predictors of serious disorders in adulthood. Oland and Shaw (2005) point out that uncontrolled behaviour is the main characteristics of externalizing behaviour. Children with externalizing behaviour problems do not have a sufficiently developed self-control ability, as well as the ability to accurately reflect feedback from their surroundings about their behaviour, so they do not notice the negative reactions of the environment to their behaviour. Also, due to the difficulties in social interactions, they tend to retreat into themselves, which can later lead to the expression of anger (Rubin et al., 1990, according to Maughan et al., 2000).

Research have also shown that children with externalizing problems have distorted selfperception, which is manifested by the tendency to express aggression, impulsivity, increased activity, etc. (Oland \& Shaw, 2005). Children with externalizing behaviour do not adjust their behavior to the demands of the environment and society, and often the sensation seeking factor, which is correlated with other forms of behaviour such as smoking, drinking alcohol, substance abuse, etc., can also occur (Romer \& Hennessy, 2007). In cases when externalizing problems are already present in the childhood, problems, that relate to social competence, school motivation and academic achievement, especially to the period of adolescence, can be expected. Unscrupulous and aggressive behaviour disrupts mutual relations with peers and consequently leads to rejection from other students, as well as to lower school achievement (Mikas, 2012). Macuka and associates (2012) point out that externalizing problems are often determined by anger, hostility, disregard for social norms, and that there are difficulties in accepting and respecting authority, leading to increased conflicts with parents, teachers and other adults. 


\section{Dimensions and types of family relationships}

To explore the family relationships, the Circumflex model (Olson \&Gorall, 2003) was used as a theoretical framework, which highlights three dimensions of family relationships: cohesiveness, flexibility and communication.

Olson (1996) defines family cohesiveness as: "the emotional bond that family members feel towards each other". The author highlights four degrees of cohesiveness: non-binding (very low), separation (low to moderate), connection (moderate to high), networking (very high). Functional family systems on the level of cohesiveness represent the families in the balanced part of the model (separation and connectivity), in which individuals are able to be separated and related to the family at the same time. On the other hand, dysfunctional family systems mark the families whose cohesion is unbalanced (non-binding and networking).

Casual family systems often have an extreme emotional detachment whose members engage in very few relationships with other family members, neglecting togetherness and closeness; while the network family systems are characterized by diffused boundaries, unclear differentiation and great pressure towards unity, indicating a lack of autonomy. When it comes to the dimensions of cohesiveness, functionality represents a balance between intimacy and commitment with tolerance for differences and separation, whereby the borders are semi permeable, and the roles clearly defined.

Flexibility or family adaptability, is "the amount of change in the family leadership, the distribution of roles and rules of mutual relations" (Olson, 1996), and according to the circumflex model there are four types of adaptability (flexibility): rigidity (very low level), structurality (low to moderate), flexibility (moderate to high) and chaos (very high). The central levels of adaptability, structurality and flexibility, are balanced and suitable for family functioning. Family systems with a structural relationship tend to possess a relative democracy, in which there is a certain degree of concurrence that includes children; while family systems characterized by a flexible relationship have a democratic approach to decision-making, in which there are open-ended arrangements and where children are actively involved. On the contrary, unbalanced family relationships are either rigid type, which implies the dominance of one person in a family with a high degree of control and rigid rules, or a chaotic type characterized by disorganization, role variability, lack of clear rules and noncohesiveness.

Communication is viewed as a mitigating dimension that helps family systems to change their levels of cohesion and flexibility. It is defined as an expression of thoughts and feelings in an assertive way, as well as a careful and accurate reception of others' thoughts and feelings. It is assessed through the listening and speaking skill, the clarity of speech, the ability to follow the continuity of conversation, as well as respecting and honouring others versus standing themselves out.

\section{Correlation between family relationships and communication and externalizing behaviour problems}

Numerous studies indicate the correlation between family relationships and communication and externalizing behavioural problems. In terms of emotional relationships, research shows that warmth, the acceptance of children and the response to their emotional needs by 
parents, are in a negative correlation with behaviour problems. Bares and associates (Bares et al., 2011) point out that children, who are more likely to perceive parental attitudes towards them as positive (warm, supportive and non-hostile), manifest a lower degree of delinquent and aggressive behaviour. Bosco and associates (Bosco et al., 2003) show that the perceived acceptance by parents is associated with the reduction in externalizing problems in both genders. Longitudinal studies have shown that a warm emotional relationship is associated with a reduction in behaviour problems over time. Fosco and associates (2012) report that the experience of children being connected with their father (experiencing intimacy, trust in parents, reliance on their advice and satisfaction when they are together) predicts a decline in the level of antisocial behaviour, substance abuse and socializing with the problematic peers. Skaramella and associates (2002) found that the lack of parental warmth and support is associated with delinquency by contributing to an increase in the earlier antisocial behaviour of children and entering into relationships with peers with deviant behaviour. Parental establishment of a discipline by applying roughness - physical punishment and verbal aggression, is associated with a greater degree of externalizing problems in the behaviour of adolescents (Bailey et al., 2009; Voydano, 2004; Wissink, Dekovic \& Meijer, 2006, according to Stojkovic et al., 2013).In the aforementioned study by Scaramella and associates (2002), care and involvement of parents, which is negatively correlated with the delinquent behaviour of adolescents, is characterized, in addition to emotional warmth and support, by consistent discipline and positive support, in contrast to hostility and coercion, as well as a high degree of monitoring of adolescents.

\section{RESEARCH METHODOLOGY}

\section{Subject and Purpose of the research}

The goal of the research was to determine whether the families of children with externalizing behaviour problems differed by the level of functionality in relation to the families of children without the presence of externalizing behaviour problems measured by the scale of FACES IV. The hypothesis is that families of children with externalizing behaviour problems are less functional compared to families of children without the presence of externalizing behaviour problems. Families of the children with externalizing behaviour problems will have higher scores in unbalanced dimensions, while in balanced dimensions, as well as in the dimensions of family communication and family satisfaction, they will have lower scores in regard to families of children without the presence of externalizing behaviour problems.

\section{Methods and instruments}

For assessing emotional, social and behaviour problems of children and youth, Achenbach System of Empirically Based Assessment (ASEBA, Youth Self-Report - YSR) (Achenbach \& Rescorla, 2001) was used. Externalizing behaviour problems are measured on the basis of the aggression scale (Aggressive Behaviour) and rule breaking behaviour scale (Rule-Breaking Behaviour). The scale of aggression consists of seventeen items (for example: "Frequently in a physical fight" or "Physically attacking others").The rule breaking scale contains sixteen items (for example: "Swears and uses bad words" or "Breaks school rules"). The scales are three point scales, participants responding by selecting one of the offered answers: "incorrect", "partly true", "true". High scores on the scales indicate numerous and serious difficulties, and based on normative data, it can be determined whether the score is in the "normal", "border" or "clinical" range. 
Youth Self-Report - YSR has good metric characteristics, with measured test-retest reliability of 0.82 and an internal consistency of 0.71 to 0.95 for empirically-designed problem scales (Achenbach \& Rescorla, 2001).

The FACES IV scale package, which provides a comprehensive assessment of the dimensions of family cohesion and family flexibility using six scales, was used to determine the quality of family relationships and communication within families with children with externalizing behaviour problems(Olson \& Gorall, 2003).

FACES IV consists of eight scales, six scales from FACES IV and one scale from family communication and family satisfaction. FACES IV contains 62 items, 42 items from FACES IV, 10 on family communication, and 10 on family satisfaction. FACES IV measures the dimensions of Family Cohesion and Family Flexibility using six scales. There are three scales for the dimension of cohesion (disengagement, balanced cohesion and complexity) and three scales for the dimension of flexibility (rigidity, balanced flexibility and chaos).

The reliability of the FACES IV scale measures 0.845 , indicating a satisfactory level of reliability (Olson, 2009). The reliability coefficient of the scales used on our sample indicates that the $a$ coefficient ranges from 0.75 to 0.88 , for cohesiveness 0.82 , for flexibility 0.79 , and for communication 0.81 . Regarding the reliability of the sub-scales, they are: for disengagement 0.75 , for balanced cohesion 0.87 , for complexity 0.77 , for rigidity 0.82 , for balanced flexibility 0.86 and for chaos 0.88 .

\section{The research sample}

The study sample consisted of 735 students from fifth to eighth grade, both genders, aged 11 to 14 years. The survey was conducted in eight primary schools in Belgrade. One class out of fifth, sixth, seventh and eighth grade was chosen from each school, a total of 32 classes.

Table 1. Participants structure by school age and gender

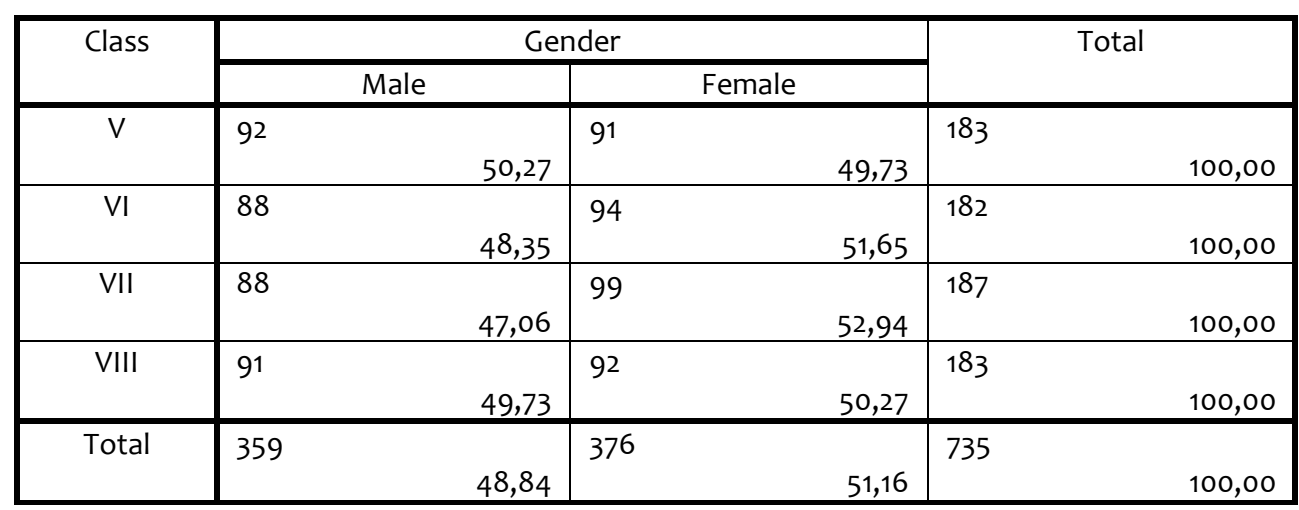




\section{RESEARCH RESULTS}

\section{Prevalence of externalizing problems of students behaviour}

The results which were obtained after processing the data collected by using the YSR scale (Table 2) show that of the total number of students who made the sample of the study $(\mathrm{N}=$ 735), in 135 students the presence of externalizing problems was noted, whose score $T>63$ belongs to "clinical" range.

Table 2. Descriptive indicators of scores from YSR's

\begin{tabular}{|l|c|c|c|}
\hline & Externalizing problems & SD \\
\hline Score & $\mathrm{N}$ & $\mathrm{M}$ & 7,57 \\
\hline Students with T > 63 & 135 & 35,61 & 5,82 \\
\hline Students with T = 60-63 & 36 & 14,45 & 6,89 \\
\hline Students with T < 60 & 564 & 31,18 & \\
\hline
\end{tabular}

A further study involved 135 students who showed the presence of externalizing behaviour problems, who were in the first group, and 135 students who did not show the presence of externalizing behaviour problems, who formed the second group.

Table 3. Structure of students with externalizing problems by school age and gender

\begin{tabular}{|c|c|c|c|c|c|c|}
\hline \multirow[t]{2}{*}{ Grade } & \multicolumn{4}{|c|}{ Gender } & \multirow{2}{*}{\multicolumn{2}{|c|}{ Total }} \\
\hline & \multicolumn{2}{|c|}{ Male } & \multicolumn{2}{|c|}{ Female } & & \\
\hline \multirow[t]{2}{*}{ V } & 17 & & 11 & & 28 & \\
\hline & & 60,71 & & 39,29 & & 100,00 \\
\hline \multirow[t]{2}{*}{ VI } & 21 & & 17 & & 38 & \\
\hline & & 55,26 & & 44,74 & & 100,00 \\
\hline \multirow[t]{2}{*}{ VII } & 27 & & 9 & & 36 & \\
\hline & & 75,00 & & 25,00 & & 100,00 \\
\hline \multirow[t]{2}{*}{ VIII } & 29 & & 12 & & 41 & \\
\hline & & 70,73 & & 29,27 & & 100,00 \\
\hline \multirow[t]{2}{*}{ Total } & 94 & & 41 & & 135 & \\
\hline & & 69,63 & & 30,37 & & 100,00 \\
\hline
\end{tabular}

Relations and communication in families of students

Table 4. Scale quality of family relations

\begin{tabular}{|l|c|c|c|c|c|}
\hline & $\mathrm{N}$ & Min & Max & M & SD \\
\hline $\begin{array}{l}\text { Balanced } \\
\text { cohesion }\end{array}$ & 135 & 11,00 & 28,00 & 19,5900 & 3,78066 \\
\hline $\begin{array}{l}\text { Balanced } \\
\text { flexibility }\end{array}$ & 135 & 8,00 & 29,00 & 18,5300 & 3,69178 \\
\hline Rigidity & 135 & 12,00 & 35,00 & 23,1000 & 3,22987 \\
\hline Structurality & 135 & 8,00 & 24,00 & 16,8300 & 3,54291 \\
\hline
\end{tabular}




\begin{tabular}{|l|c|c|c|c|c|}
\hline Chaotic & 135 & 15,00 & 35,00 & 27,9300 & 3,40928 \\
\hline Disengagement & 135 & 12,00 & 35,00 & 26,6200 & 4,15958 \\
\hline Communication & 135 & 8,00 & 27,00 & 16,0600 & 4,11962 \\
\hline $\begin{array}{l}\text { Satisfaction with } \\
\text { family }\end{array}$ & 135 & 9,00 & 27,00 & 17,0900 & 4,02101 \\
\hline
\end{tabular}

Based on the expression of balanced scales, shown through percentile scores, it is concluded that the participants assessed their families moderately to poorly related $(M=19.5900)$, moderately to poorly flexible $(M=18.5300)$, and that Communication and Satisfaction with the family are at the low level $(M=16.0600$ and $M=17.0900)$. When it comes to the expression of unbalanced scales, it is concluded that their families have very high degrees of rigidity, chaos and disengagement, while their scale is structural at the central level. We have come up with these findings on the basis of the table for converting the raw into the percentile scores in the FACES IV manual.

Observing the obtained results, we can conclude that students with externalizing behaviour problems live in family types that have problematic functioning, that is, they live in types of families where the quality of family relationships is low and is characterized by poor connectivity and adaptability, poor communication and dissatisfaction with the family. In family types such as the flexibly unbalanced type, a chaotic disengagement type and unbalanced type, there is a low level of healthy and high level of problematic behaviour in which either one person dominates or the family relationships are disorganized.

\section{The link between external behavioral problems and student assessments about the functionality of their family in terms of cohesion, flexibility and communication}

Table 5. Connection of externalizing behavior problems and student's assessment on the functionality of their families

\begin{tabular}{|l|c|c|}
\hline \multirow{4}{*}{ Cohesion } & & Externalizing problems \\
\cline { 2 - 3 } & $\mathrm{r}$ & 0,290 \\
\cline { 2 - 3 } & $\mathrm{p}$ & 0,000 \\
\hline \multirow{3}{*}{ Flexibility } & $\mathrm{N}$ & 111 \\
\cline { 2 - 3 } & $\mathrm{r}$ & 0,277 \\
\cline { 2 - 3 } & $\mathrm{p}$ & 0,280 \\
\hline \multirow{3}{*}{ Rigidity } & $\mathrm{N}$ & 111 \\
\cline { 2 - 3 } & $\mathrm{r}$ & 0,239 \\
\cline { 2 - 3 } & $\mathrm{P}$ & 0,282 \\
\hline Structurality & $\mathrm{N}$ & 111 \\
\cline { 2 - 3 } & $\mathrm{r}$ & 0,218 \\
\cline { 2 - 3 } & $\mathrm{P}$ & 0,051 \\
\cline { 2 - 3 } & $\mathrm{N}$ & 111 \\
\hline Chaos & $\mathrm{r}$ & 0,215 \\
\cline { 2 - 3 } & $\mathrm{P}$ & 0,190 \\
\cline { 2 - 3 } & $\mathrm{N}$ & 111 \\
\hline
\end{tabular}




\begin{tabular}{|l|c|c|}
\hline \multirow{4}{*}{ Disengagement } & $\mathrm{r}$ & 0,221 \\
\cline { 2 - 3 } & $\mathrm{p}$ & 0,002 \\
\cline { 2 - 3 } & $\mathrm{N}$ & 111 \\
\hline Communication & $\mathrm{r}$ & 0,290 \\
\cline { 2 - 3 } & $\mathrm{p}$ & 0,000 \\
\cline { 2 - 3 } & $\mathrm{N}$ & 111 \\
\hline Satisfaction with family & $\mathrm{r}$ & 0,261 \\
\cline { 2 - 3 } & $\mathrm{p}$ & 0,000 \\
\cline { 2 - 3 } & $\mathrm{N}$ & 111 \\
\hline
\end{tabular}

"The difference is statistically significant at the 0.01 level

'The difference is statistically significant at the 0.05 level

By calculating the Pearson correlation coefficient, a statistically significant correlation between the externalizing behaviour problems and the student's assessment of the functionality of their family in terms of cohesion (0.290), flexibility (0.277), communication (0.290) and family satisfaction (0.261) were established. This means that students with externalizing behaviour problems have very little satisfaction with the family, in which communication is lacking, where family members are poorly connected and insufficiently prepared to adapt to change.

The results of this research have confirmed the findings of many previous research. The presence of externalizing behaviour problems in students of this age can be explained and brought into association with the period of puberty and adolescence, which is consistent with the results of earlier studies (Bongers et al., 2003; Twenge \& Nolen Hoeksema, 2002). Research findings of numerous studies (Barrera et al., 1995; Jenkins \& Smith, 1990; 1991; Peterson \& Zill, 1986; Raudino et al., 2013; Buist et al., 2004, according to Kovacevic et al., 2013) show that inadequate devotion to parents, in the form of lack of trust, inadequate communication with parents and alienation, can result in externalizing problems, which is in line with our data.

\section{CONCLUSIONS}

This research has confirmed that families of children with externalizing behaviour problems differ in terms of functionality, measured using the FACES IV scale, in relation to the families of children without the presence of externalizing behaviour problems. We have found that families of children with externalizing behaviour problems have a lower score on dimensions: balanced cohesion, balanced flexibility, family satisfaction and family communication, and higher on dimensions: disengagement, rigidity, chaos and complexity. These results are in line with the results of other studies.

The limitation of this study is methodological and refers to the method of assessing family functionality, that is, self-assessment, which always carries the risk of subjectivity. Recommendation for future similar studies would certainly be the inclusion of more family members and checking the conformity of their assessment, which would give a more realistic picture of family functionality. 
There are numerous implications of the obtained results about the clear link between family functionality and externalizing behaviour problems. First of all, this is the first research in our social environment that has largely confirmed the results obtained in previous research. Simple and easy self-assessment of the family, using this questionnaire, can be useful in working with young people belonging to risk groups, and by using it in a quick and efficient way those families, in which the work with the family would be of special importance, could be identified. Functional scores on some of the dimensions of this questionnaire, that indicate family strength, can be of benefit to family therapists. It is important to use these forces in the further work with the family and to strengthen these positive aspects of the family functioning.

\section{REFERENCES}

Achenbach, T. M. \& Rescorla, L. A. (2001). Manual for the ASEBA school-age forms and profiles. Burlington: University of Vermont, Research Center for Children, Youth and Families.

Bares, C. B., Andrade, F., Delva, J., \&Grogan-Kaylor, A. (2011). Personality and parenting processes associated with problem behaviours: A study of adolescents in Santiago, Chile, Social Work Research, 35(4), 227-240.

Bongers, I. L., Koot, H. M., van der Ende, J. \& Verhulst, F. C. (2003). The normative development of child and adolescent problem behavior,Journal of Abnormal Psychology, 112 (2), 179-192.

Bosco, G. L., Renk, K., Dinger, T. M., Epstein, M. K., \&Phares, V. (2003). The connections between adolescents' perceptions of parents, parental psychological symptoms, and adolescent functioning, Journal of Applied Developmental Psychology, 24(2), 179-200.

Carlson, C.L., Tamm, L., \& Hogan, A.E. (1999). The child with oppositional defiant disorder and conduct disorder in the family. In Quay, H. C. \& Hogan. A. E. (Eds.), Handbook of disruptive behaviour disorders (pp. 337-352). New York: Kluwer Academic Press.

Fosco, G. M., Stormshak, E. A., Dishion, T. J., \& Winter, C. E. (2012). Family relationships and parental monitoring during middle school as predictors of early adolescent problem behaviour, Journal of Clinical Child and Adolescent Psychology, 41(2), 202-213.

Kovacevic Lepojevic, M. I Zunic Pavlovic, V. (2013). Privrzenost roditeljima i eksternalizovani problemi u ponasanju adolescenata [Attachment to parents and externalising behaviour problems in adolescents], Socijalna misao, 20 (4), 87-95.

Macuka, I., Smojver-Azic, S., Buric, I. (2012). Posredujuca uloga emocionalne regulacije u odnosu roditeljskog ponasanja i prilagodbe mladih adolescenata. Drustvena istrazivanja, 21 (2), 383-403.

Matthys, W. \& Lochmann, J.E. (2010). Oppositional defiant disorder and conduct disorder in childhood. Chichester: John Wiley \& Sons Ltd.

Maughan, B., Picklesa, A., Rowe, R., Costello, E.J., \& Angold, A. (2000). Developmental trajectories of aggressive and non-aggressive conduct problems, Journal of Quantitative Criminology, 16, 199-221.

McMahon, R.J., Wells, K.C., \& Kotker, J.S. (2006). Conduct problems. In Mash, E. J. \&Barkey, R. A. (Eds.), Treatment of childhood disorders (pp. 137-269). New York: The Guilford Press. 
Mikas, D. (2012). Utjecaj emocionalnih i ponasajnih problema na skolski uspjeh ucenika. Pedagogijska istrazivanja, 9(1-2), 83-101.

Oland, A., \& Shaw, D. (2005). Pure versus co-occurring externalizing and internalizing symptoms in children: Potential role of socio-developmental milestones. Clinical Child and Family Psychology Review, 8 (4), 247-270.

Olson, D. \& Garrall, H. M. (2003). Circumplex model of morital \& family system. Minneapolis: University of Minnesota and Life Innovation.

Olson, D. (1996). Clinical Assesmentand Treatment Interventions Using the family Circumplex model. In Florece W. \& Kaslow, Handbook of relation diagnosis and dysfunctional families patterns (59-77). New York: John Wiley \& Sons.Inc.

Olson, D. H. (2009). Faces IV and the Circumplex model: validation study. Minneapolis: University of Minnesota and Life Innovation.

Romer, D. \& Hennessy, M. (2007). A biosocial-affect model of adolescent sensation seeking: the role of affect evaluation and peer-group influence in adolescent drug use, Prevention Science, 8, 89-101.

Scaramella, L., Conger, R., Spoth, R., \& Simons, R. (2002). Evaluation of social contextual model of delinquency: a cross study replication, Child Development, 73(1), 175-195.

Stojkovic I., Dimoski S., Eminovic F. (2013). Problemi u ponasanjuinjihovikorelati u adolescenciji - longitudinalnastudija [Behavioral problems and their correlates in adolescence longitudinal study], Specijalna edukacija i rehabilitacija, 12 (4), 455-479.

Twenge, J. M., \& Nolen-Hoeksema, S. (2002). Age, gender, race, socioeconomic status, and birth cohort difference on the children's depression inventory: A meta-analysis, Journal of Abnormal Psychology, 111, 578-588.

Vilotijevic, N. (2002) Porodicna pedagogija. Beograd: Uciteljski fakultet. Vrsac: Visa skola za obrazovanje vaspitaca.

\section{Biographical note:}

Maša Đurišić, master teacher, works in Primary school "Veselin Masleša" in Belgrade, Republic of Serbia, also a PhD student of the Faculty of Special Education and Rehabilitation in Belgrade, where she is currently preparing her doctoral dissertation. Special topic of interest: the treatment and prevention of behavioral disorders. She wrote a number of research studies and participated in several projects and international conferences. 